Pacific Journal of Mathematics

ON THE ABSOLUTE MATRIX SUMMABILITY OF A FOURIER 


\section{ON THE ABSOLUTE MATRIX SUMMABILITY OF A FOURIER SERIES}

\section{ARIBINDI SATYANARAYAN RAO}

In this paper, the author gives sufficient conditions for a Fourier series at an arbitrary but fixed point to be absolutely matrix summable.

1. Introduction. Let $\sum_{0}^{\infty} u_{n}$ be an infinite series with partial sums $s_{n}$, and let $A=\left(a_{n k}\right)$ be a triangular infinite matrix of real numbers (see Hardy [2]). The series $\sum u_{n}$ is said to be absolutely summable $A$, or summable $|A|$, if

$$
\sum_{1}^{\infty}\left|\tau_{n}-\tau_{n-1}\right|<\infty
$$

where

$$
\tau_{n}=\sum_{k=0}^{n} a_{n k} s_{k}
$$

Let $f(t)$ be a Lebesgue-integrable function of period $2 \pi$, with Fourier series

$$
\frac{1}{2} a_{0}+\sum_{1}^{\infty}\left(a_{n} \cos n t+b_{n} \sin n t\right) \equiv \sum_{0}^{\infty} A_{n}(t) .
$$

With a fixed point $x$, we set

$$
\begin{gathered}
\phi(t)=\phi_{x}(t)=\frac{1}{2}[f(x+t)+f(x-t)], \\
\Phi(t)=\int_{0}^{t}|\phi(u)| d u .
\end{gathered}
$$

We establish the following theorem for the absolute matrix summability of the Fourier series (1.1) of $f(t)$ at $t=x$.

THEOREM. Let $A=\left(a_{n k}\right)$ be a triangular infinite matrix of real numbers such that $\Delta a_{n k}=a_{n k}-a_{n: k+1}$ is monotonic with respect to $n \geqq k$ for each fixed $k \geqq 0$.

Let $\alpha(t)$ be a positive function such that $t^{r} / \alpha(t)$, for some $r$ with $0<r<1$, is nondecreasing for $t \geqq t_{o}$. Suppose that

$$
\sum_{n=1}^{\infty} \frac{n\left|a_{n n}\right|}{\alpha(n)}<\infty
$$




$$
\left|\Delta a_{m, 0}\right|+\sum_{n=1}^{m-1} \frac{n\left|\Delta a_{m n}\right|}{\alpha(n)}=O(1) \quad \text { as } m \rightarrow \infty .
$$

Further, let

$$
\Phi(t)=O\left[\frac{t}{\alpha(1 / t)}\right] \quad \text { as } t \rightarrow 0+.
$$

If all of the above conditions hold, then the Fourier series (1.1) of $f(t)$ at $t=x$ is summable $|A|$.

We shall require the following lemmas.

LEMma 1. If $\alpha(t)$ is defined as in the theorem, then

$$
\int_{t_{0}}^{t} \frac{d u}{\alpha(u)}=O\left[\frac{t}{\alpha(t)}\right] \quad \text { for all } t \geqq t_{o} .
$$

Proof.

$$
\begin{aligned}
\int_{t_{0}}^{t} \frac{d u}{\alpha(u)} & =\int_{t_{0}}^{t} \frac{u^{r}}{\alpha(u)} \cdot \frac{d u}{u^{r}} \\
& \leqq \frac{t^{r}}{\alpha(t)} \int_{t_{0}}^{t} \frac{d u}{u^{r}} \leqq \frac{t^{r}}{\alpha(t)} \cdot \frac{t^{-r+1}}{1-r}=O\left[\frac{t}{\alpha(t)}\right] .
\end{aligned}
$$

Lemma 2. If $A=\left(a_{n k}\right)$ is defined as in the theorem and if

$$
\begin{gathered}
\sum_{n=0}^{\infty}\left|t_{n}\right| \cdot\left|a_{n n}\right|<\infty, \\
\sum_{n=0}^{m-1}\left|t_{n}\right| \cdot\left|\Delta a_{m n}\right|=O(1) \quad \text { as } m \rightarrow \infty,
\end{gathered}
$$

where

$$
t_{n}=\sum_{k=0}^{n} s_{k},
$$

then $\sum u_{n}$ is summable $|A|$.

Proof. By Abel's transformation,

$$
\begin{aligned}
\tau_{n}-\tau_{n-1} & =\sum_{k=0}^{n}\left(a_{n k}-a_{n-1, k}\right) s_{k} \\
& =\sum_{k=0}^{n-1}\left(\Delta a_{n k}-\Delta a_{n-1, k}\right) t_{k}+a_{n n} t_{n} .
\end{aligned}
$$

Now

$$
\begin{aligned}
& \sum_{n=1}^{m} \sum_{k=0}^{n-1}\left|\Delta a_{n k}-\Delta a_{n-1, k}\right| \cdot\left|t_{k}\right| \\
= & \sum_{k=0}^{m-1}\left|t_{k}\right| \cdot\left(\sum_{n=k+1}^{m}\left|\Delta a_{n k}-\Delta a_{n-1, k}\right|\right)=\sum_{k=0}^{m-1}\left|t_{k}\right| \cdot\left|\Delta a_{m k}-a_{k k}\right| .
\end{aligned}
$$


Thus,

$$
\begin{aligned}
& \sum_{n=1}^{m}\left|\tau_{n}-\tau_{n-1}\right| \leqq \sum_{n=0}^{m-1}\left|t_{n}\right| \cdot\left|\Delta a_{m n}\right|+2 \sum_{n=0}^{m}\left|t_{n}\right| \cdot\left|a_{n n}\right|=O(1) \\
& \text { as } m \rightarrow \infty, \text { by }(2.2) \text { and }(2.3) .
\end{aligned}
$$

This completes the proof of the lemma.

3. Proof of the Theorem. We write

$$
s_{n}(x)=\sum_{0}^{n} A_{k}(x), t_{n}(x)=\sum_{0}^{n} s_{k}(x) .
$$

By (1.6), there exists $\delta(0<\delta<1)$ such that

$$
\Phi(t) \leqq K \frac{t}{\alpha(1 / t)} \quad \text { for } 0<t \leqq \delta,
$$

where $K$ is a positive constant (not necessarily the same at each occurrence). Now, for $n>\delta^{-1}$,

$$
\begin{aligned}
\pi t_{n}(x) & =\int_{0}^{\pi} \phi(t)\left[\frac{\sin (n+1)(t / 2)}{\sin (t / 2)}\right]^{2} d t \\
& =\int_{0}^{n^{-1}}+\int_{n^{-1}}^{\delta}+\int_{\delta}^{\pi}=I_{1}+I_{2}+I_{3}, \text { say. }
\end{aligned}
$$

We observe that

$$
\left[\frac{\sin (n+1) \cdot(t / 2)}{\sin (t / 2)}\right]^{2}= \begin{cases}O\left(n^{2}\right) & \text { for } \sin t / 2 \neq 0 \text { and } n \geqq 1 \\ O\left(1 / t^{2}\right) & \text { for } 0<t \leqq \pi\end{cases}
$$

So, by (3.1),

$$
\left|I_{1}\right| \leqq K n^{2} \int_{0}^{n^{-1}}|\phi(t)| d t \leqq K \frac{n}{\alpha(n)} .
$$

Further, assuming $t^{r} / \alpha(t)$ nondecreasing for $t \geqq \delta^{-1}$,

$$
\begin{aligned}
\left|I_{2}\right| & \leqq K \int_{n^{-1}}^{\delta} \frac{|\phi(t)|}{t^{2}} d t \\
& =K\left\{\left[\frac{\Phi(t)}{t^{2}}\right]_{n^{-1}}^{\delta}+2 \int_{n^{-1}}^{\delta} \frac{\Phi(t)}{t^{3}} d t\right\} \\
& \leqq K\left[\frac{\Phi(\delta)}{\delta^{2}}+\int_{n^{-1}}^{\delta} \frac{d t}{t^{2} \alpha(1 / t)}\right] \\
& =K\left[\frac{\Phi(\delta)}{\delta^{2}}+\int_{\delta^{-1}}^{n} \frac{d u}{\alpha(u)}\right] \\
& \leqq K \frac{n}{\alpha(n)} \quad \text { as } n \rightarrow \infty, \text { by (2.1). }
\end{aligned}
$$


Obviously,

$$
I_{3}=O(1) .
$$

From (3.2), (3.4)-(3.6), it follows that

$$
t_{n}(x)=O\left[\frac{n}{\alpha(n)}\right] \quad \text { as } n \rightarrow \infty .
$$

Hence

$$
\begin{aligned}
\sum_{n}^{\infty}\left|t_{k}(x)\right| \cdot\left|a_{k k}\right|=O\left[\sum_{n}^{\infty} \frac{k}{\alpha(k)}\left|a_{k k}\right|\right] & =o(1) \\
& \text { as } n \rightarrow \infty \text {, by (1.4). }
\end{aligned}
$$

Moreover,

$$
\begin{aligned}
\sum_{0}^{m-1}\left|t_{n}(x)\right| \cdot\left|\Delta a_{m n}\right| & =\left|t_{0}(x)\right| \cdot\left|\Delta a_{m_{0}}\right|+O\left[\sum_{1}^{m-1} \frac{n}{\alpha(n)} \cdot\left|\Delta a_{m n}\right|\right] \\
& =O(1) \quad \text { as } m \rightarrow \infty \text {, by (1.5). }
\end{aligned}
$$

Now the theorem follows from Lemma 2.

4. Nоте. Let $A=\left(a_{n k}\right)$ be a triangular infinite matrix of real numbers such that $a_{n n} \geqq 0$ for all $n \geqq 0$ and $\Delta a_{n k}$ is nondecreasing with respect to $n \geqq k$ for each fixed $k \geqq 0$. Let $\alpha(t)$ be defined as in the theorem, and let

$$
\Delta a_{m, 0}+\sum_{n=1}^{m} \frac{n\left(\Delta a_{m n}\right)}{\alpha(n)}=O(1) \quad \text { as } m \rightarrow \infty .
$$

Then, if the condition (1.6) holds, the Fourier series (1.1) of $f(t)$ at $t=x$ is summable $|A|$.

Proof. Let

$$
\tau_{n}(x)=\sum_{k=0}^{n} a_{n k} s_{k}(x)
$$

Then

$$
\begin{aligned}
\sum_{n=1}^{m} & \left|\tau_{n}(x)-\tau_{n-1}(x)\right| \\
& \leqq \sum_{n=1}^{m} \sum_{k=0}^{n}\left|\Delta a_{n k}-\Delta a_{n-1 k}\right| \cdot\left|t_{k}(x)\right| \\
& =\sum_{k=1}^{m}\left|t_{k}(x)\right|\left(\sum_{n=k}^{m}\left|\Delta a_{n k}-\Delta a_{n-1, k}\right|\right)+\left|t_{0}(x)\right| \sum_{n=1}^{m}\left|\Delta a_{n 0}-\Delta a_{n-1} 0\right| \\
& =\sum_{k=1}^{m}\left|t_{k}(x)\right|\left(\Delta a_{m k}\right)+\left|t_{0}(x)\right|\left(\Delta a_{m_{0}}-a_{0}\right)
\end{aligned}
$$




$$
\begin{aligned}
& \leqq\left|t_{0}(x)\right|\left(\Delta a_{m, 0}\right)+O\left[\sum_{k=1}^{m} \frac{k}{\alpha(k)}\left(\Delta a_{m l}\right)\right], \quad \text { by }(3.7) \\
& =0(1) \quad \text { as } m \rightarrow \infty, \text { by }(4.1) .
\end{aligned}
$$

So the required result follows.

I thank Professors A. Meir and A. Sharma for providing me financial support from their N.R.C. grants during the preparation of this paper.

\section{REFERENCES}

1. S. N. Bhatt, An aspect of local property of $\left|N, p_{n}\right|$ summability of a Fourier series, Indian J. Math. 5 (1963), 87-91.

2. G. H. Hardy, Divergent Series, (Oxford, 1949).

3. L. McFadden, Absolute Nörlund summability, Duke Math. J., 9 (1942), 168-207.

Received May 7, 1971.

UnIVersity of Alberta

EdMONTON, Canada 



\section{PACIFIC JOURNAL OF MATHEMATICS}

\section{EDITORS}

H. SAMELSON

Stanford University

Stanford, California 94305

C. R. HobBY

University of Washington

Seattle, Washington 98105
J. DUGUNDJI

Department of Mathematics

University of Southern California

Los Angeles, California 90007

RICHARD ARENS

University of California

Los Angeles, California 90024

\section{ASSOCIATE EDITORS}

E. F. BECKENBACH

B. H. NeumanN

F WoLF

K. YoshidA

\section{SUPPORTING INSTITUTIONS}

UNIVERSITY OF BRITISH COLUMBIA

UNIVERSITY OF SOUTHERN CALIFORNIA

CALIFORNIA INSTITUTE OF TECHNOLOGY

UNIVERSITY OF CALIFORNIA

MONTANA STATE UNIVERSITY

STANFORD UNIVERSITY

UNIVERSITY OF NEVADA

NEW MEXICO STATE UNIVERSITY

OREGON STATE UNIVERSITY

UNIVERSITY OF OREGON

OSAKA UNIVERSITY

UNIVERSITY OF TOKYO

UNIVERSITY OF UTAH

WASHINGTON STATE UNIVERSITY

UNIVERSITY OF WASHINGTON

$\stackrel{*}{*} \stackrel{*}{*} \stackrel{*}{*}{ }^{*}{ }^{*}$ MMEICAN MATHEMATICAL SOCIETY

NAVAL WEAPONS CENTER

Printed in Japan by International Academic Printing Co., Ltd., Tokyo, Japan 


\section{Pacific Journal of Mathematics}

\section{Vol. 42, No. $1 \quad$ January, 1972}

Tage Bai Andersen, On Banach space valued extensions from split faces ........

David Marion Arnold, A duality for quotient divisible abelian groups of finite

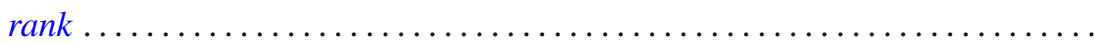

Donald Pollard Ballou, Shock sets for first order nonlinear hyperbolic

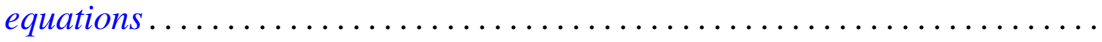

Leon Brown and Lowell J. Hansen, On the range sets of $H^{p}$ functions .........

Alexander Munro Davie and Arne Stray, Interpolation sets for analytic

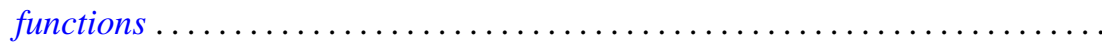

M. G. Deshpande, Structure of right subdirectly irreducible rings. II . . . . . . . . .

Barry J. Gardner, Some closure properties for torsion classes of abelian

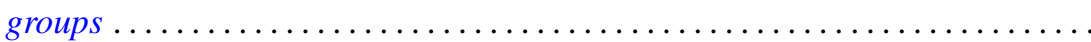

Paul Daniel Hill, Primary groups whose subgroups of smaller cardinality are

direct sums of cyclic groups . . . . . . . . . . . . . . . . . . .

Richard Allan Holzsager, When certain natural maps are equivalences .........

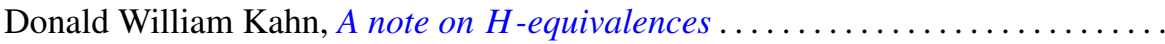

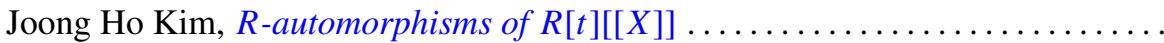

Shin'ichi Kinoshita, On elementary ideals of polyhedra in the 3-sphere.........

Andrew T. Kitchen, Watts cohomology and separability...

Vadim Komkov, A technique for the detection of oscillation of second order

ordinary differential equations .

Charles Philip Lanski and Susan Montgomery, Lie structure of prime rings of characteristic 2

Andrew Lenard, Some remarks on large Toeplitz determinants . .

Kathleen B. Levitz, A characterization of general Z.P.I.-rings. II .

Donald A. Lutz, On the reduction of rank of linear differential systems

David G. Mead, Determinantal ideals, identities, and the Wronskian ...

Arunava Mukherjea, A remark on Tonelli's theorem on integration in product

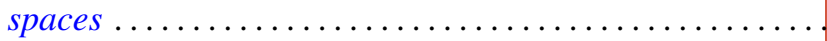

Hyo Chul Myung, A generalization of the prime radical in nonassociative rings.

John Piepenbrink, Rellich densities and an application to unconditionally nonoscillatory elliptic equations.

Michael J. Powers, Lefschetz fixed point theorems for a new class of multi-valued maps .

Aribindi Satyanarayan Rao, On the absolute matrix summability of a Fourier

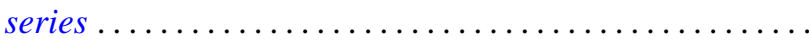

T. S. Ravisankar, On Malcev algebras ......................... 227

William Henry Ruckle, Topologies on sequences spaces . . . . . . . . . . . . . 235

Robert C. Shock, Polynomial rings over finite dimensional rings . . . . . . . . . 251

Richard Tangeman, Strong heredity in radical classes . . . . . . . . . . . . . . 259

B. R. Wenner, Finite-dimensional properties of infinite-dimensional spaces . . . . 267 